\title{
¿SOCIOLOGÍA DE LA LITERATURA? ¿QUÉ ES ESO? LEAMOS A GISELLE SAPIRO
}

\author{
SOCIOLOGY OF LITERATURE? WHAT IS THAT? \\ LET'S READ GISĖLE SAPIRO
}

\author{
Cristopher Montero Corrales*
}

RESUMEN

Este texto es una reseña del libro La Sociología de la Literatura de Gisèle Sapiro. Este libro evidencia las formas de construcción del objeto de estudio entre la Sociología y la Literatura, así como, los principales marcos teóricos que se han ocupado de la reflexión del texto literario, su creación y la recepción social, a través de un compendio de estudios $y$ reflexiones que han abordado el texto literario como hecho social. Esta obra finaliza con una muestra de los espacios emergentes de la Sociología de la Literatura. Resulta ser un texto de consulta importante para la reflexión sociológica de la literatura por las diversas exploraciones teóricas y enfoques que plantea en cuatro capítulos: Teoría y enfoques sociológicos de la literatura, Las condiciones sociales de producción de las obras, La Sociología de las obras y Sociología de la recepción.

PALABRAS CLAVE: SOCIOLOGÍA * LITERATURA * GISÈLE SAPIRO * ESTUDIO LITERARIO * RESEÑA BIBLIOGRÁFICA

\section{ABSTRACT}

This text is a review of the book "The Sociology of Literature" of Gisèle Sapiro. She shows the forms of construction of an object of study between the sociology and the literature, as well the principles of teoric frames that have gotten into the thought of the literary text, his creation and the social reception. This was done gathering studies and thoughts that have use it as a social act. Finally with a piece of the emerging spaces of the literature of sociology. It results been an important consultant text for the sociological reflection of literature for the variety theorical explorations and different points of view on four chapters: Theory and Approaches sociological of the literature, The social conditions of the production of the pieces, The sociology of the pieces, and Sociology of reception.

KEYWORDS: SOCIOLOGY * LITERATURE * GISÈLE SAPIRO * LITERARY STUDIES * BOOK REVIEW 
Una manifestación contra la evasión fiscal y la literatura podrían entenderse fácilmente como hechos muy distintos; lo cierto es que ambos son hechos sociales. Ambos transmiten representaciones sociales de una época según sea el grupo social, por ejemplo. Con esta afirmación clara, "el hecho literario en tanto que hecho social" (Sapiro, 2016, p.13), Gisèle Sapiro inicia el libro La Sociología de la Literatura (Fondo de cultura económica, 2016, traducción de Laura Fólica). El libro está dividido en cuatro capítulos: Teoría y enfoques sociológicos de la literatura, Las condiciones sociales de producción de las obras, La Sociología de las obras y Sociología de la recepción. El libro inicia delimitando el objeto de estudio de la Sociología de la Literatura y evidenciando cómo se ha construido según una diversidad de enfoques o corrientes teóricas donde expone un manejo teórico de ese espacio confuso entre la Sociología y la Literatura.

Entender que la novela costarricense $E l$ fuego cuando te quema (Víquez, 2015) no pudo haber sido escrita sin Alí Víquez, pero este autor es un punto que aman $u$ odian en el entramado social e histórico costarricense. Esta es la tensión que hace nacer la Sociología de la Literatura. "Análisis interno" y "análisis externo" le llaman. Puesto en otras, la relación entre historia e individualidad.

En el caso de la obra literaria, no alcanza la intención del autor para una interpretación textual que explique el hecho literario, ya que muchas veces el autor no sabe, cabalmente, que se escribe $y$, por otro, tampoco conoce las consecuencias sociales de su escritura en la recepción del texto y de los usos sobre lo que se escribe en el presente o en el pasado. Así que se está en un terreno entre la creación, la historia y la recepción social del texto para armar el objeto de estudio de la Sociología de la Literatura. Puesto en otras palabras, salir de lo ególatra del "genio" que escribe o del frío anonimato entre la multitud. No es extraña esta paradoja en la Sociología, como lo señala Sapiro (2016): "Desde esta óptica, el enfoque sociológico del hecho literario es concebido como el estudio de las mediaciones entre las obras y las condiciones sociales de su producción" (p.16).
En el siglo XIX, la descripción de la vida social era tarea de la literatura realista, por ejemplo, en el cuento de Balzac "La cúpula de los inválidos", un pasaje de la aristocracia a las luces y cloacas de la burguesía y, de lo asombroso-mágico, a los naturales efectos del alcohol en el cuerpo. De esos efectos del alcohol en el cuerpo podía dar cuenta la ciencia $y$, bueno, la Sociología se vuelve "la ciencia de las costumbres". Este tipo de literatura toma el derecho de descripción de lo real y se aleja un paso más de lo que se había alejado la literatura realista, de lo poético del siglo XviII. Tal vez por esto se considere aburrido el "estudio de las trayectorias individuales" frente al mítico oxímoron "creador increado".

Así, el primer movimiento de la Sociología de la Literatura fue hacia la historia de la Literatura: la Literatura como una copia de la realidad social, un principio de mimesis, evidenciando la visión de mundo de la novela decimonónica. Además, su relación con la forma de la ciencia se hace presente en "Las leyes de la historia literaria" (Sapiro, 2016), un documento de Gustave Lamson, a solicitud de Durkheim. En el siguiente paso, se empieza el afianzamiento en los géneros que hoy se entienden como Literatura, por ejemplo.

De ahí, el siguiente paso de la Sociología de la Literatura sería preguntarse: ¿la gente consume literatura por opinión del crítico o por recomendación del entorno cercano? Para posteriormente enfocarse en encuestas sobre libros, sobre lectura: las evidencias cuantitativas de la democratización cultural. Lo anterior son muestras de que el arte no es un fin en sí mismo, sino en su recepción y sus características. Efectivamente, un enfoque positivista. Para explicarlo con algunos ejemplos en la sociedad costarricense: los principales tipos de libros que leen las personas en Costa Rica son las novelas en un $34,9 \%$ de los casos o decir que las mujeres leen más que los hombres, leen más por placer y que, mayormente, leen novelas con lo que superan a los hombres con 8,9 puntos porcentuales (Instituto Nacional de Estadísticas y Censos, 2016).

Frente al análisis interno, surge la reflexión marxista: sí, la literatura es parte de la 
superestructura. Desde ese poderoso marco teórico surge la autonomía frente a la mímesis o al mecanicismo de la visión de mundo.

"¿Acaso hay que ver en la literatura un simple reflejo del mundo social, como reivindica la literatura realista o la expresión de una ideología que vehicula la visión de mundo?" (Sapiro, 2016, p.32). Señala Gisèle Sapiro sobre las interrogantes de los marxistas que a su vez tenían contradicciones internas, ¿las formas literarias y las condiciones sociales? (Lukács) o ¿condiciones sociales y recepción? (Gramsci). Aunque, claramente no se puede dar cuenta de la obra por la reducción ideológica (Adorno), y mucho menos afirmar que no existe autor sino su clase social (Goldmann), pero el pueblo no es mero receptáculo de la clase social de los autores, también hay otras literaturas: Literatura popular (Williams), para dar un ejemplo. Con esto nace el concepto de producción frente al de creación. La cuestión es clara, las mediaciones son muy complejas y diversas en la materialización de la obra.

Pero esto implica que no haya mayor especificidad en el hecho literario, es decir, es como cualquier otra actividad social. Para salir de esa "indeterminación social" se pone énfasis en el campo literario. La autora señala que es Pierre Bourdieu "quien hace de la literatura un objeto de pleno derecho de la sociología" (2016, p.36). Esta aseveración, sin duda discutible, depende de qué entiende la autora por Sociología. La relación entre Ulises y el tipo Burgués, que exponen Max Horkheimer y Theodor Adorno en "Dialéctica de la Ilustración" (2007) sería otro ejemplo de "Sociología de la Literatura".

Frente a la "autonomía" marxista nace el concepto de "campo" que se entiende como un espacio de posibilidades que se hacen efectivos en las decisiones de los escritores y las escritoras. Permite entenderlo de manera sistematizada. Por ejemplo, decidir entre una narración celeste o realista para un relato de infancia. O, escoger el escenario del Caribe costarricense para los relatos de mujeres cuyos nombres inician con " $\mathrm{A}$ " como lo hace Arabella Salaverry (2016) en "Impúdicas". Esta decisión se hace según el "capital cultural", es decir, el reconocimiento $y$ la experiencia en el campo $y$ fuera de este.

En otras palabras, una persona que escriba que ganó premios nacionales e internacionales, tendrá mayores recursos para establecer una concepción de literatura. Se pueden observar dos aspectos importantes: el campo es el escenario de tensión de lo "externo e interno" y lo poco poético de las categorías Bouirdeanas. Esto facilita su operacionalización. Diferencia sustancial con lo abstracto y épico de "totalidad" de George Luckás.

Podría verse como algo sin importancia, pero los significantes o las formas construyen el sentido. Así, como el ensayo muestra algo con su ensayística plana y desapasionada: una manera de entender la escritura sociológica.

También sucede con lo desencantado del "sistema literario" de Even-Zohar, concentrado en "designar las relaciones entre productores (escritores) y consumidores (lectores)" (p.41), pero, nuevamente, permitiendo hacer preguntas tan precisas como la que hace Even-Zohar (1999) en La posición de la literatura traducida en el polisistema literario:

"¿Qué tipo de relaciones puede establecerse entre obras traducidas que son presentadas como hechos consumados, importadas de otras literaturas, desgajadas de sus contextos locales $y$, en consecuencia, neutralizados desde el punto de vista de las luchas entre centro y periferia?" (p.224).

También aporta para identificar lógicas entre países o al interno de regiones. Por ejemplo, la poesía cívico político costarricense que llama Alfonso Chase, frente a la poesía comprometida nicaragüense o la poesía revolucionaria salvadoreña. Formas de ser un escritor comprometido que varían. Además, permite salir del escritor para incluir editores y personal de difusión para entender "lo literario" más allá del misterio del creador o del chisme-biográfico, aunque haya sido tan exitoso editorialmente, es un punto que aportan estos abordajes desde las ciencias sociales.

Este libro permite conocer las distintas maneras de llamar el debate "interno-externo". 
- Ha tenido otros nombres como Sociogenética o Psicogenética en Norbert Elias-, cuando las ciencias sociales asumen la literatura como un campo de estudio. Es uno de los aportes de la autora para entender la Sociología de la Literatura y sus diversidades para armar el objeto de estudio: "Ni expresión inmediata de la visión del mundo de una época ni reflejo directo de la realidad, la literatura escapa a la alternativa entre racionalismo y empirismo" (Sapiro, 2016, p.48).

Así, frente a este escape de la literatura como evidencia empírica clara, como un reflejo, la Sociología de la Literatura se concentra en tres maneras: 1) las condiciones sociales de producción de las obras, tales como, la lógica del mercado y la literatura industrial; 2) las instancias de difusión, el papel del editor o el reclutamiento social; y 3) la profesionalización de escritores: "el derecho de entrada es claramente mucho más caro en términos de capitales económico y cultural, y lo es más aún para las mujeres que para los hombres" (Sapiro, 2016), caracterizándose este enfoque por una diversidad de instancias para armar el objeto de estudio (instancias de formación, instancias de reconocimiento, instancias de producción y difusión, instancias de consagración, grupos o escuela literarias). Como se puede ver, el texto literario se excluye por no ser evidencia empírica como tal, como si lo haría la entrevista o la encuesta.

Un enfoque que recupera el texto sería "la Sociología de las obras" que entiende el texto como una manera de "vehicular" otro tipo de discursos, por ejemplo, el de los naturalistas del siglo XIX, con lo que se refractó el discurso científico: "las obras literarias constituyen una fuente para estudiar las representaciones sociales" (Sapiro, 2016, p.79). La mirada socio-crítica, las relaciones de clases sociales se concentran en las representaciones pero "no alcanza con analizar las representaciones vehiculadas en una obra literaria para comprender su especificidad: el trabajo de puesta en forma es lo que convierte esa materia en un producto literario identificado como tal" (Sapiro, 2016, p.86).

De esta manera, pone al cientista social en la disyuntiva de interpretar no solo "la visión de mundo" sino la forma que lo hace, es decir, una aproximación estética. "Literatura e identidad", "Literatura y nación", "la perspectiva colonial", "singularidad estética", "estrategias de escritura y de autor", sería algunos de los temas a tratar desde este enfoque.

Por último, la Sociología de la Recepción, concentrada en cómo se han recibido los textos, en el análisis y usos, más allá de su producción. Por ejemplo, la jerarquización de las obras por el éxito en la crítica, en las ventas o por los premios ganados, o formas de censura e, inclusive, los pleitos literarios, forma con la cual se evidencian los juicios de valor sobre las obras. Esta resulta ser otra de las formas que ha tomado el objeto de estudio en la Sociología de la Literatura.

La autora no solo da un panorama de lo que ha sido la Sociología de la Literatura en el siglo xx, sino que, además, muestra nuevos escenarios de cómo se puede ampliar el objeto de estudio en la actualidad; por ejemplo, los festivales de literatura o la Sociología de la lectura predominantemente cualitativa, también explorada en un libro llamado Hacía una antropología de la lectura (2015), recopilado por Néstor García Canclini, con un enfoque que se distancia de la importancia de la familia según la escuela francesa $y$ pone el énfasis en las comunidades de las cuales se participa: un muchacho que lee "solo" en Starbucks, lo hace para ser observado de cierta manera, por ciertas personas que no son su familia.

Asimismo, Sapiro pone su atención en los nuevos hábitos de lectura rompiendo los análisis que se centran en la lectura de libros o en los hábitos de lectura en voz baja o alta, una práctica solitaria o comunal.

Por último, habría que diseñar dispositivos de encuesta que permitan traducir empíricamente las reflexiones sobre el desarrollo de las capacidades empáticas y las virtudes "Democráticas" que alentaría la experiencia de lectura de ficción (Sapiro, 2016, p.137).

La Sociología de la Literatura de Gisèle Sapiro es un diverso escenario que muestra 
las formas de construir un objeto de estudio, en una disciplina que no ha sido, mayormente, institucionalizada y capaz de una continua renovación. Devela cómo se ha armado un objeto de estudio y la posibilidad de aportar desde esa construcción a la disciplina sociológica. Su erudición, no solo al manejar las fuentes sino en albergar formas dispares de entender un objeto desde una misma disciplina hace de este texto un recurso vital para entender qué es eso de la Sociología de la Literatura.

\section{REFERENCIAS}

Even-Zohar, I. (1999). La posición de la literatura traducida en el polisistema literario. En M. Iglesias Santos (Ed.), Teoría de los Polisistemas. Arco (pp. 223-231).
García, N. (2015). Hacia una antropología de los lectores. Ariel.

Horkheimer, M. y Adorno, T. (2007). La dialéctica de la ilustración. AKAL.

Instituto Nacional de Estadísticas y Censos. (2016). Encuesta Nacional de Cultura 2016: Principales Resultados. INEC.

Salaverry, A. (2016). Impúdicas. URUK.

Sapiro, G. (2016). La Sociología de la Literatura. Fondo de Cultura Económica.

Víquez, A. (2015). El fuego cuando te quema. EUNED.

Zohar, E. (2007). Polisistemas de cultura. Universidad de Telaviv.

Fecha de ingreso: 03/10/2019

Fecha de aprobación: 13/10/2020 
